\title{
Reality is wilder
}

\section{How a terrifying interview led to fun doing physics.}

\section{Gregory Benford}

ob interviews can be harrowing, but few ultimately change one's career directions. One afternoon in 1967, a personnel clerk at the Lawrence Radiation Laboratory, California, ushered me into a large, messy office, saying only that 'someone' wanted to ask me a few questions.

I was being interviewed for what was then (and still is) the best-paying postdoctoral position in physics. About to become a freshly minted $\mathrm{PhD}$ from the University of California, San Diego, I wondered if this was about security clearance. Instead, a distracted Edward Teller sat behind an untidy desk that was piled high with physics journals. Nobody had told me that Teller insisted on taking the measure of every postdoctoral candidate. "We didn't want you to be nervous," someone said later. It worked - I was merely terrified.

He was the most daunting job interviewer imaginable, a famous physicist and director of the laboratory, looming large in a central mythology of modern science - the A-bomb. In that next hour, no one disturbed us as Teller quizzed me in detail about my thesis in solid-state plasmas. Attentively, he turned every facet over and over, spying undiscovered nuances, overlooked difficulties, a calculation a bit askew. I struggled to keep up, incoming questions splattering like bugs on my conceptual windshield. By the time you see the problem, it's too late.

My thesis explored how strong magnetic fields could bind extra electrons to hydrogenlike impurities in indium antimonide - an effect later verified. Teller saw many implications, and soon stood beside me at the blackboard, dashing out equations. He was brilliant, leaping ahead of myjittery explanations to see connections that I had only vaguely sensed. His mind darted as swiftly as any I had ever encountered. Within minutes, I was sweating. That one hour lasted days.

To my vast surprise, I apparently passed inspection. At the end, there was a long pause and he gestured for me to sit in a wooden chair beside the blackboard. I sank into it with relief, showering chalk from my hands onto his desk. He then announced, “The most important kvestion of all," and, leaning closer with a sudden scowl, then asked, "Vill you be villing to vork on vhatever comes up?"

Unbidden, images from Stanley Kubrick's film Dr. Strangelove leaped to mind. He had already asked if I would be willing to work on

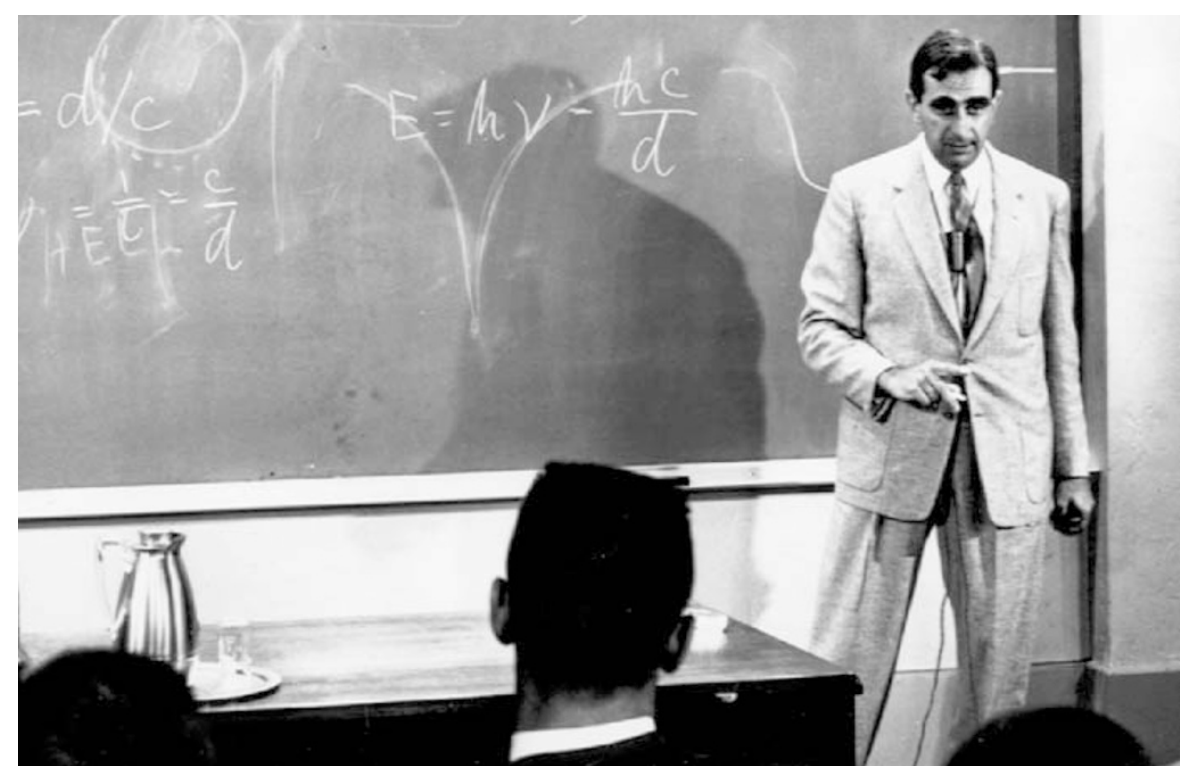

Edward Teller (above) cast an imposing presence over modern physics, intimidating the author (below).

thens but this was even more open-ended. However, Teller had impressed me as a deep, reflective man. I had grown up in the shadow of the cold war. My father was a career army officer and our family had lived in occupied Japan and Germany. These were advanced nations, yes, but the greatest can blunder the most. It seemed to me that the sheer impossibility of using nuclear weapons was the best, indeed the only, way to avoid strategic conventional war, whose aftermath I had seen in shattered Tokyo and Berlin.

So I agreed. There was no Dr. Strangelove. Teller just wanted to do physics and have fun. Within a few weeks, I had a job offer — for whatever came up. In the next four years at Livermore, I had a chance to work with Teller and the other wild talents, such as Lowell Wood, who relished the collision of colourful imagination and careful analysis.

I got involved with the study of tachyons, the theoretically possible particles that can travel faster than light. Not the sort of thing one imagines a 'weapons lab' doing, but Teller allowed the theorists a wide range. When the tachyon idea popped up in the physics journals, Teller thought they were highly unlikely, and I agreed — but worked on them anyway out of sheer speculative interest. Moving faster than light implies particles can travel backwards in time.

Teller invoked a different argument against tachyons. Echoing Enrico Fermi's famous question, "Where are they?" that asked why aliens, if they are plentiful in the galaxy, haven't visited us by now, Teller noted that if tachyons existed, "Vhy haven't they been sent? Vere are our messages from the future?"

My answer was that nobody had built a tachyon receiver yet. Neat, but perhaps too neat. Surely nature would not disguise such a profound effect. With Bill Newcomb and David Book, I published the paper'The Tachyonic Antitelephone' (Phys. Rev. D 2, 263-265; 1971). We destroyed the existing arguments, which had avoided time-travel paradoxes by reinterpreting tachyonic trajectories moving backward in time as their antiparticles moving forward in time. Without using a single equation, we showed that imposing a signal on the tachyons - sending a message - defeated the reinterpretation, so causality problems remained. Time plays a strange role in physics. Paradoxes are hard to rule out. I later wrote a novel about this, Timescape, which has been in print a quarter of a century, suggesting that fundamental puzzles remain.

This pattern, speculation leading to detailed theory, is one I have often encountered. I even wrote novels about it, a hobby that has at times taken my career in odd directions. Ideas blossom from imagination, but they must be tested against reality; that, as I learned from Teller, is the essence of science. The received wisdom of science is quite prissy, speaking of how anomalies in data lead theorists to explore models, which are then checked by dutiful experimenters, and so on. Reality is wilder than that.

Gregory Benford is in the Department of Physics, University of California, Irvine, California

92697-4575, USA. 